\title{
Domestic drones: the politics of verticality and the surveillance industrial complex
}

\author{
Ciara Bracken-Roche \\ Department of Sociology, Queen's University, Kingston ON, M6P 2H2, Canada \\ Correspondence to: Ciara Bracken-Roche (c.bracken-roche@queensu.ca)
}

Received: 26 January 2016 - Revised: 31 May 2016 - Accepted: 14 June 2016 - Published: 15 July 2016

\begin{abstract}
Drones are being introduced as innovative and cost-effective technologies for civil, commercial, and recreational purposes in the domestic realm. While the presence of these technologies is increasing, regulations are being introduced in order to ensure their safe and responsible use. As drones are adopted for a number of purposes, the "de facto practices settle around it, rendering change much more difficult" (Gersher, 2014), and so the policy debates must consider all contingencies and unintended consequences of their use. This paper discusses the background of unmanned aerial vehicles (UAVs), their role as surveillance technologies, and how they reinforce asymmetries in power and visibility that contribute to a politics of verticality, ultimately arguing that surveillance concerns must become part of the discussion at the policy and regulatory level in order to mitigate any harms. Where drones are already used for care and control as technologies of surveillance, privileged use of drones by public and police agencies could further reinforce a politics of verticality (Weizman, 2002), resulting in specific types of space, risk, and population management.
\end{abstract}

These devices are woven up in myths of technological superiority, objectivity, and control that help support their adoption. By means of their supposed accuracy and precision, drone systems may encourage the hostile targeting of threats in military settings while further inuring people to invisible monitoring in domestic spheres.

Wall and Monahan 2011, 240

\section{Introduction}

This paper discusses drones in the domestic realm and the implications of their widespread adoption and use for civil and commercial purposes. The primary concerns raised in relation to domestic drones are safety (as often cited by regulatory agencies and industry manufacturers; Goodyear, 2015) and privacy (the focus of work by academic and civil liberties organizations, Beltran, 2015; Bracken-Roche et al., 2014; Stanley and Crump, 2011). Safety has been the focus of much discussion, shaping policy and regulation that have emerged around drone technologies, and unfortunately, less importance has been placed on privacy, human rights, or civil liberties. However, as I shall argue, privacy, human rights, and civil liberties questions are sharply raised by the new kinds of surveillance made possible by these remotely operated aerial craft. Looking at these related matters through the lens of surveillance studies, this paper argues that domestic drones have the potential not only to alter our sociotechnical environment (see Wall and Monahan, 2011), but our political lives as well. As is the case with many technologies that transfer from the "military industrial complex" into domestic policing (Haggerty and Ericson, 1999), unmanned aerial vehicle (UAV) technologies are being developed, with corresponding policies and practices that purport to govern them being introduced in an ad hoc fashion beside them. This coconstruction of technology and policy is not unique to UAV technologies (Science and Technology Studies, as a field, has demonstrated this trend across new technologies), but it is important to examine in this case because it further highlights the level at which domestic policies can be shaped by the surveillance industry. Regulations governing the use of UAV technologies in the domestic sphere are primarily being written by industry stakeholders and public safety and transport regulators; this has certainly been the case in the Canadian 
context (Bracken-Roche et al., 2014; Gersher, 2014). However, the extent to which the concerns of government and industry-stakeholder groups align with those of academics and civil libertarians has yet to be seen. It might be that appropriate regulation and deployment of UAVs in a timely manner may not be possible if the concerns raised by these technologies for civil liberties, privacy, and surveillance are taken into consideration. Regulating drones in a privacy protective manner does not directly benefit the state or industry stakeholders profiting from surveillance applications and a security agenda (Bracken-Roche et al., 2014; Gersher, 2014; Jacobstein, 2013).

\section{A politics of verticality}

This paper investigates how drones contribute to a "politics of verticality" (Weizman, 2002) in the domestic context that cannot be adequately addressed in existing policies, or through policy alone. A brief background of UAVs, the novel concerns they pose as a technology of surveillance, and a case study will highlight why these technologies are so significant for our sociotechnical landscape. More so, without directly addressing civil liberties, privacy, and surveillance concerns, the use of civil and commercial drones has the potential to fall into typical applications in the military/surveillance industrial complex (see Ball and Snider, 2013 for examples) and be used for crime control, national security, and public safety. When Weizman (2002) speaks of a politics of verticality, he speaks to the fact that a map cannot express the geopolitical realities of society, and that it requires "an Escher-like representation of space, a territorial hologram in which political acts of manipulation and multiplication of the territory transform a two-dimensional surface into a three-dimensional volume". A politics of verticality has emerged with drones in the domestic realm, not only in the physical sense, but institutionally and organizationally. On the one hand, the use of drones brings the third dimension of physical space back to the fore, and questions as to what happens when a bird's eye view - as opposed to a fixed, terrestrial gaze - is adopted. Additionally, on the other hand, the organizations, policy, and regulations that have emerged with drones tend to represent traditional hierarchies of governance, with a top-down structure from government, industry, and manufacturers setting the rules, and the public at large being expected to accept these various mandates (Gregory, 2011). The use of drones in the domestic realm reinforce the primacy of vision, and the supposed omnipotence and omniscience associated with it, both in symbolic and material terms (Mieszkowski, 2012; Virilio, 1994).

\section{Dominant drone discourses}

The dominant debates around drones in the domestic realm tend to highlight regulatory issues emerging in western democracies (Klauser and Pedrozo, 2015; Bracken-Roche et al., 2014; Finn and Wright, 2012) and the challenges posed by hobbyist drone users, including issues such as the "peeping drone" (Davison, 2014) and drones flying near airports (Young, 2015). News media also highlight their use for focused and innocuous tasks such as accident scene surveying by law enforcement agencies (Lamcja, 2015), crop monitoring by farmers (Cornell, 2015), and energy and pipeline surveying (Pachner, 2015). Current domestic UAV debates centre on regulations, safety, and benign uses; never mind that many regulatory solutions such as geofencing (Tucker, 2015) or serial number registration (Koebler, 2015) can be overcome by hacking devices or by simply building a homemade drone. Geofencing is software that would be programmed into drones that would prohibit their operation in particular airspace, such as airports or government buildings, while serial number registration would require drone users to register their drone's serial number into a database so that the drone can be traced back to them. It is important to recall that drones were first used as weapons of war by the United States at the end of the last century (Rogers and Hill, 2014; Singer, 2009). They have been given extensive media coverage for their role in US-led reconnaissance and targeted strikes in Afghanistan, Iraq, and Pakistan (Ahmed, 2013; Wall and Monahan, 2011). Drones are promoted in military as well as civil and commercial operations for dealing with the three Ds: dull, dirty, and dangerous tasks (Singer, 2009). This discourse argues that drones reduce the "man hours" required for tasks, reduce collateral damage and decrease risk for individuals, and gain access to places that people might not otherwise be able to access. Therefore, it is argued that drones are used for the protection of communities and populations, as well as to promote the development of industry and commerce (Jacobstein, 2013). However, this line of argument is problematic because it does not acknowledge the ways in which the introduction of UAV technologies can fundamentally alter our sociotechnical environment, eroding expectations of privacy and fundamental democratic rights (due to the chilling effect of the technologies, amongst other implications) (Clarke, 2014).

\section{Drones and the sociotechnical environment}

As drones are incorporated into the domestic landscape, the politics of verticality introduces new elements to the sociotechnical environment that fundamentally alter relationships of power and visibility, with the potential to intensify preexisting tensions that exist in society. The addition of drones to our sociotechnical space highlights the pervasive structuring of everyday life by surveillance technologies, and how the speed and ubiquity with which surveillance can be carried out is privileged to particular individuals, organizations, and public agencies in particular spaces and places; it also highlights how access to the technolo- 
gies and the awareness about how to deploy them is privileged (Bauman and Lyon, 2012; Murakami Wood, 2007). Drones can further contribute to the dissolution of public space as a stage for protest and political negotiation in two ways. Firstly, when individuals from the public, civil liberties groups, and academia are excluded from drone policy development, where government and industry have a seat at the table, then the discourse and policymaking discussion will often negate the implications of these technologies for privacy, human rights, and civil liberties (Hayes, 2012). Secondly, the visibility that the technologies offer can be used to prohibit protests and raise concerns about privacy to the extent that individuals will no longer feel that they are free to assemble, and so drones transform many spaces that reshape social life (Clarke, 2014; Bauman and Lyon, 2012; Finn and Wright, 2012; Murakami Wood, 2007). Therefore, power relations and tensions are further intensified by the new politics of verticality and the visibility made possible by drones. The adoption of UAVs domestically necessarily reinforces the importance of airspace in national and public security policies (Adey et al., 2011) as the deployment of drones affects the relationship that the state has with its citizens, in terms of the use of the technologies by public organizations as well as the implications on citizens when widespread use is permitted. This further reinforces existing tensions around the technologies. How different groups understand the technologies, and therefore how technologies are perceived, can be a barrier to their adoption as well as potentially damaging to the relationship between drone users and those subject to them.

\section{Surveillance challenges and implications}

The adoption of drones in the domestic realm, by government and public agencies, as well as commercial organizations, highlights the primacy of the visual and makes the surveillance and monitoring of large sections of civil life possible, whether or not the technologies are being used for surveillance and data collection in policing and public safety (Denes, 2011). The current outcome of UAV use is not necessarily for the benefit and concerns of individuals but seems to perpetuate asymmetries in visibility and power between government and technology industry stakeholders and the public at large. Therefore space is transformed by both political acts and the technologies at play within society, and drones within the domestic and urban realms are contributing to this transformation (see Adey et al., 2011; Graham, 2013a, b), and the use of drones within the domestic realm contribute to this politics of verticality. Without understanding the intricacies and implications of surveillance by drones, the potential benefits and harms, then how can policy attempt to regulate the technologies appropriately? Understanding this approach requires an understanding of surveillance and the implications of surveillance. Lyon (2007) defines surveillance, gen- erally, as "the focused, systematic and routine attention to personal details for purposes of influence, management, protection or direction", and so while not all drones may be performing surveillance all of the time, they all have the capability. Marx's (2002) understanding of "new surveillance" can also be used to categorize drone technologies, as new surveillance "extends the senses and has low visibility or is invisible", and it "is more comprehensive, often involving multiple measures". Marx's understanding of surveillance focuses on an increase in the amount of data collected, the remote operation of the technology, less coercive data collection, a routinization of surveillance, and the idea that a technology can employ multiple measures in combination (ibid.).

UAVs display unique features as tools of surveillance including, but not limited to, their having remote vision and having no on-board pilot. This is a subtle but important quality to note as distinctive features in these technologies present new and distinct challenges (as compared with other modes of aerial or video surveillance), and therefore, must be examined both independently and in conjunction with other surveillance technologies. UAVs differ from other forms of visual surveillance, notably terrestrial camera surveillance, due to their aerial capabilities and increased mobility. Additionally, their increased mobility and aeriality appears to give visual surveillance new possibilities in comparison to other traditional modes of visual surveillance like CCTV, which is fixed and terrestrial (Finn and Wright, 2012). However, due to the variation in the capabilities of UAVs, their payload technologies, and the ways that they can collect data, UAVs present several unique privacy challenges. Indeed, "the prospect of cheap, small, portable flying video surveillance machines threatens to eradicate existing practical limits on aerial monitoring and allow for pervasive surveillance" (Stanley and Crump, 2011).

UAVs differ from other technologies of aerial surveillance, such as helicopters, as they are less conspicuous in terms of both audibility and their visibility to those being surveilled (Finn and Wright, 2012). Perhaps the most significant feature of UAVs in terms of surveillance implications and marketability of the technologies is the range of possible technologies with which they can be equipped (in drone parlance known as "payload"). The multidimensional nature of these technologies and their payloads gives them a seemingly endless range of surveillance capabilities, and thus allows UAVs to be applied for a seemingly endless numbers of tasks and applications (Bracken-Roche et al., 2014; Cavoukian, 2012). While the idea of eyes in the sky may be unsettling for many people, more concerning are the payload technologies with which drones can collect data, raising further questions about their data collection and sharing capabilities. The operator can see the data in real time as drones operate through a video link but data can also be streamed to cloud storage as it is collected (Jacobstein, 2013). In the age of big data, drone technologies add yet another layer to the systems of surveillance and data collection (Jensen, forthcoming). Video 
feeds can be watched live or streamed to the cloud, while simultaneously being run through facial recognition programs (Hsu and Chen, 2015), just as individuals are monitored and tracked, through their smartphones or closed circuit television, by other components of the surveillance assemblage.

\section{The surveillance industrial complex}

Analyses of the surveillance practices that permeate our daily lives often "examine how its practice has become more widespread via technologies used in warfare being diffused into everyday usage by the capitalist enterprise" (Ball, 2002, 573). The "military industrial complex," and the "surveillance industrial complex," both highlight the fusion of civilian and military interests globally and within states, "made possible by the "complementarities" of government and corporate "needs"," (Ball and Snider, 2013). Others have spoken to the ways in which these complexes create a revolving door between industry and government, establishing partnerships at the domestic and international level, that can lead to corporate interests and earnings being prioritized over the public good (Hayes, 2012). There is also a direct effect which stems from the outsourcing of so-called "dual use" civilian and military surveillance tools. Each new surveillance technology is seen as a tool for gathering, transmitting, and analysing data. Therefore, in responding to risk and threats, surveillance technologies are used to assess situations in both civilian and military scenarios. These developments are associated with new innovations in surveillance technologies, which have become cheaper and more sophisticated at once. The drone can be utilized in military scenarios for battlefield reconnaissance, but is also deployed by emergency responders to survey car accidents from above.

\section{Civilian drone use gone wrong: a case and theory}

Given this history, it is no surprise that some interpret drones as antagonistic technologies. For instance, in March 2014 in Canada, the Ontario Provincial Police (OPP) flew an UAV over the Tyendinaga Reserve where First Nations protesters had a rural road partially blocked in order to take aerial photos of the protest scene (Bowman, 2014). This deployment was for "public safety operations", but raised questions about civil liberties. The reaction of the protestors, media, and public was to ask why the OPP felt the need to escalate the situation and "intimidate" protestors with the use of UAVs (ibid.). In response to the drone launch, members of the public and journalists tweeted: "Now who is escalating tensions here?", "are drones ethical in this game?", "They are treating this like a military operation?”, and “@OPP_ER dispatch drones to intimidate peaceful protest...”. The police's response was to state that "unmanned aerial vehicles (UAV) are an economical way to take pictures. It is a tool used in investigations." (@OPP_ER). It is not surprising that individuals responded in this way given the drones' long history of targeting and assassinating, and it is this military history that adds complexity to public perceptions around these technologies (Thompson and Bracken-Roche, 2015; Chamayou, 2015; Gregory, 2011). Those participating in the protest and those who reacted to the UAV over social media were reacting to the police agency "bringing military logic, technology and experience squarely into the realm of policing and civil security" (Hayes, 2012).

However, while people might react to the drones' history as a military technology, they might also be reacting to their qualities of remote vision and remote piloting. The question of visibility is particularly important to UAVs due to their remote vision and piloting as well as the politics of verticality that they bring into being through their use domestically. Some scholars highlight that visibility "lies at the intersection of the two domains of aesthetics (relations of perception) and politics (relations of power)" (Brighenti, 2007:324). This conception highlights the significance of vision in surveillance theory because visibility is not just being able to see or be seen, but it is more symbolic of how both power and visibility tend to be asymmetrical (ibid.). Brighenti (2007) argues that the non-reciprocal vision that UAVs possess leads to a different way of seeing, and feeling of being seen. Therefore, while protestors at the Tyendinaga blockade were already interacting with police on the ground, the situation did not escalate until the drone was launched, resulting in asymmetrical vision between the parties involved (Bowman, 2014). Individuals who are being surveilled using technological mediation cannot look back or establish eye contact with another individual, and therefore are always made suspect to a certain extent because they are being looked at through a one-way mode of surveillance. Simmel's (1969) discussion on the visual constitution of society is also relevant here as he claims that the mutual glance, the reciprocity of eye-toeye contact, is, according to some, a basic constituent of society. "More radically, following Simmel's insight on the reciprocity of the eye-to-eye relation, they (individuals) are not even fully human" (Brighenti, 2007:337). The implication here is that a reciprocal gaze is so intrinsic to social relations that when a gaze is only one way, or when it is between human and technology, it is not only asymmetrical but also potentially dehumanizing. Brighenti believes that such dehumanization can occur to an extent for the observed, and "possibly, although indirectly, of the beholder, too" (ibid.).

\section{Conclusions}

The idea that total vision results in omniscience has been a dominant theme in surveillance theory (e.g. Foucault, 1997) and in practice as demonstrated by the sheer abundance of surveillance technologies used in contemporary (Lyon and Haggerty, 2012). Additionally, while drones do not offer total vision, they offer the illusion of it, and are technologies 
based on "the will to see all, know all, at every moment, everywhere, the will to universalised illumination" (Virilio, 1994). However, an omniscient and perpetual gaze is never really possible; the gaze is always partial because no matter how detailed it is or from what vantage point it is viewing, it can never fully conceptualize everything that it takes in. The gaze, whether vertical or horizontal, mobile or static, necessarily flattens the various material and symbolic layers that it perceives. In an attempt to take in all views and knowledge, the gaze results in a reduction of difference that homogenizes people and expands the scope of who might be under surveillance (Wall and Monahan, 2011).

Surveillance technologies have allowed increasing modes of seeing and monitoring beyond the limitations of situated space and place. The deployment and use of UAVs is not just about the technology or about the social world in which they are used, but their adoption within the domestic realm contributes to a politics of verticality, and joins the surveillance assemblage where knowledge, power, identities, practices, strategies, and technologies are within a constant state of interaction with one another (Topak, 2010). Surveillance technologies that traditionally existed in military engagements, and then along borders, have now drifted into the domestic sphere and become part of a culture of control and risk management (Wall and Monahan, 2011), allowing for mobile sites of surveillance and security. Therefore, the politics and policies of verticality that allow for the deployment of drones, and that have the possibility to transform people and groups into targets, cannot be addressed separately from operating and safety concerns, but must be considered a substantial part of and side effect of the operation of UAVs. As regulatory solutions are introduced, users will find ways to get around them if they really want to. The need for safety and surveillance concerns of drones should be addressed together rather than surveillance concerns trailing behind those of safety; as while the harms may be different, they are equally real and, given their potential in the broader surveillance assemblage, are vital to address.

Acknowledgements. I would like to thank my supervisor, David Lyon, the anonymous reviewer, Shayna Gersher, Trevor Scott Milford, and Silvana Pedrozo for their invaluable comments and feedback. I am very thankful to Francisco Klauser and Silvana Pedrozo both for organizing the conference "Power and Space in the Drone Age," where I was able to discuss and formulate my ideas for this paper, and for the rich conversations that we have had on this topic since. This research was supported by the Social Sciences and Humanities Research Council of Canada.

Edited by: F. Klauser

Reviewed by: one anonymous referee

\section{References}

Adey, P., Whitehead, M., and Williams, A. J.: Introduction: Airtarget: Distance, reach and the politics of verticality, Theor. Cult Soc., 28, 173-187, 2011.

Ahmed, A.: The Thistly and the Drone: How America's War on Terror Became a Global War on Tribal Islam, Brookings, Harrisonburg, 2013.

Ball, K.: Elements of Surveillance: A New Framework and Future Directions, Information, Communication \& Society, 5, 573-590, 2002.

Ball, K. and Snider, L. (Ed.): The Surveillance-Industrial Complex:A political economy of surveillance, Routledge, London, 2013.

Bauman, Z. and Lyon, D.: Liquid Surveillance, Polity Press, Cambridge, 2012.

Beltran, D.: The Privacy Commissioner of Canada Comments on Proposed UAV Regulation, CyberLex, 2015.

Bowman, J.: Ontario police defend use of drone cameras over protes, CBC News, 2014.

Bracken-Roche,C., Lyon, D., Mansour, M. J., Molnar, A., Saulnier, A., and Thompson, S., Surveillance Drones: Privacy Implications of the Spread of Unmanned Aerial Vehicles (UAVs) in Canada, A report to the Office of the Privacy Commissioner of Canada, under the 2013-2014 Contributions Program, Surveillance Studies Centre, Queen's University, 2014.

Brighenti, A.: Visibility: A Category for the Social Sciences, Current Sociology, 55, 323-342, 2007.

Cavoukian, A.: Privacy and Drones?: Unmanned Aerial Vehicles, A report by the Information and Privacy Commissioner, Ontario, Canada, 2012.

Chamayou, G.: A Theory of the Drone, New Press, New York, 2015.

Clarke, R.: The Regulation of Civilian Drones' Applications to the Surveillance of People, Xamax Consultancy Pty Ltd., 2014.

Cornell, C.: Farmers use drones and data to boost crop yields, The Globe and Mail, 2015.

Davison, J.: Why it's hard to stop a peeping drone: Recreational use of unmanned aerial vehicles falls into grey zone of regulation, CBC News, 2014.

Denes, N.: From tanks to wheelchairs: unmanned aerial vehicles, battlefield Zionist experiments, and the transparence of the civilian, in: Surveillance and Control in Israel/Palestine: Population, Territory, and Power, edited by: Zureik, E., Lyon, D., and AbuLaban, Y., Routledge, Oxon, 171-196, 2011.

Finn, R. L. and Wright, D.: Unmanned Aircraft Systems: Surveillance, Ethics and Privacy in Civil Applications, Computer Law and Security Review, 28, 184-194, 2012.

Foucault, M.: Discipline and Punish: The Birth of the Prison, Vintage Books, London, 1997.

Gersher, S.: Regulating Spies in the Skies: Recommendations for Drone Rules in Canada, IEEE Technol. Soc. Mag., 33, 22-25, 2014.

Goodyear, S.: Drones get more popular, and the rules are getting stricter, CBC News, 2015.

Graham, S.: Foucault's Boomerang: The New Military Urbanism, Open Democracy, 2013a.

Graham, S.: The New Military Urbanism, in: The SurveillanceIndustrial Complex: A Political Economy of Surveillance, edited by: Ball, K. and Snider, L., Routledge, New York, 11-26, 2013 b. 
Gregory, D.: From a View to a Kill: Drones and Late Modern War, Theor. Cult. Soc., 28, 188-215, 2011.

Haggerty, K. D. and Ericson, R. V.: The Militarization of Policing in the Information Age, Journal of Political and Military Sociology, 27, 233-255, 1999.

Hayes, B.: The Surveillance-Industrial Complex, in: Routledge Handbook of Surveillance Studies, edited by: Ball, K., Haggerty, K. D., and Lyon, D., Routledge, Oxon, 167-175, 2012.

Hsu, H. J. and Chen, K. T.: Face Recognition on Drones: Issues and Limitations, ACM DroNet 2015, Florence, Italy, 18-22 May 2015, 2015.

Jacobstein, N.: Drones?: A 360 Degree View, World Policy J., 30, 14-19, 2013.

Klauser, F. and Pedrozo, S.: Power and space in the drone age: a literature review and politico-geographical research agenda, Geogr. Helv., 70, 285-293, doi:10.5194/gh-70-285-2015, 2015.

Koebler, J.: 8 Questions Raised by the FAA's Decision to Register Every Drone in the US, Motherboard, available at: http://motherboard.vice.com/read/8-questions-raised-by-thefaas-decision-to-register-every-drone-in-the-us, 2015.

Lamcja, I.: Canada's police forces take to the sky with drones, Metro News, 2015.

Lyon, D.: Surveillance Studies: An Overview, Polity Press, Cambridge, 2007.

Lyon, D. and Haggerty, K. D.: The Surveillance Legacies of 9/11: Recalling, Reflecting on, and Rethinking Surveillance in the Security Era, Canadian Journal of Law and Society, 27, 291-300, 2012.

Marx, G. T.: What's New about the 'new Surveillance'?: Classifying for Change and Continuity, Surveillance \& Society, 17, 18-37, 2002.

Mieszkowski, J.: Watching War, Stanford University Press, Stanford, 2012.

Murakami Wood, D.: Securing the Neurocity, Criminal Justice Matters, 68, 37-38, 2007.
Pachner, J.: How Aeryon Labs intends to keep its industrial drone business aloft, Canadian Business, 2015.

Rogers, A. and Hill, J.: Unmanned: Drone Warfare and Global Security, Palgrave Macmillan, New York, 2014.

Simmel, G.: Sociology of the Senses: Visual Interaction, in: Introduction to the Science of Sociology, 3, edited by: Park, R. E. and Burgess, E. W., University of Chicago Press, Chicago, 1969.

Singer, P. W.: Wired for War: The Robotics Revolution and Conflict in the 21st Century, Penguin, New York, 2009.

Stanley, J. and Crump, C.: Protecting Privacy from Aerial Surveillance: Recommendations for Government Use of Drone Aircraft, American Civil Liberties Union, 2011.

Thompson, S. and Bracken-Roche, C.: Understanding public opinion of UAVs in Canada: A 2014 analysis of survey data and its policy implications, Journal of Unmanned Vehicle Systems, 3, 156-175, 2015.

Topak, O.: The New Borders of EU: Surveillance, Security and European Citizenship,SGIR 7th Pan-European International Relations Conference, Stockholm, Sweden, 9-11 September 2010, 2010.

Tucker, P.: Chuck Schumer's No-Fly-Zone Rule for Drones Won't Work, Defense One, available at: http://www.defenseone. com/technology/2015/08/chuck-schumer-no-fly-zone-drones/ $119389 /, 2015$

Virilio, P.: The Vision Machine, Indiana University Press, Bloomington, 1994.

Wall, T. and Monahan, T. Surveillance and Violence from Afar: The Politics of Drones and Liminal Security-Scapes, Theor. Criminol., 15, 239-254, 2011.

Weizman, E.: Introduction to The Politics of Verticality, Open Democracy, 2002.

Young, L.: Drones increasingly buzzing too close to Canadian airports: reports, Global News, 2015. 